\title{
Plasticity in the foraging behavior of male Southern Rockhopper Penguins (Eudyptes chrysocome) during incubation in the Falkland/ Malvinas Islands
}

\author{
Klemens Pütz ${ }^{1}$ - Sabrina Harris ${ }^{2,3} \cdot$ Norman Ratcliffe $^{4} \cdot$ Andrea Raya Rey $^{2,3} \cdot$ Sally Poncet $^{5} \cdot$ Bernhard Lüthi $^{6}$
}

Received: 14 December 2017 / Revised: 21 March 2018 / Accepted: 23 March 2018 / Published online: 5 April 2018

(c) The Author(s) 2018

\begin{abstract}
Environmental changes often affect the persistence of species or populations at different spatial and temporal scales. Thus, species must either adapt to these changes or experience negative impacts at the individual or population levels. Southern Rockhopper Penguins Eudyptes chrysocome are distributed throughout the Southern Ocean and have experienced substantial declines in the past which were linked to various anthropogenic and environmental factors. The aim of this study was to investigate the foraging behavior of male Southern Rockhopper Penguins at Berkeley Sound, East Falkland, Falkland/ Malvinas Islands, during incubation, a period at-sea which is crucial for replenishing body condition between two extended fasting periods ashore. Thus, birds are forced to forage efficiently during that time to balance their energy demands. We linked their at-sea distribution and foraging behavior to satellite-derived sea surface temperatures and temperature-depth profiles which were recorded by devices attached to the birds. While Southern Rockhopper Penguins usually travel several hundreds of $\mathrm{km}$ out into the open sea on multiple-day trips during incubation, we found in our study that most birds foraged close inshore, less than $9 \mathrm{~km}$ away from their colony, and regularly returned to their breeding site. We propose that this behavior occurred in response to the close proximity of the $8{ }^{\circ} \mathrm{C} \mathrm{SST}$ isotherm and the vertical stratification of the waters therein. Also, while usually feeding pelagically in open waters, there are strong indications that Southern Rockhopper Penguins performed benthic or, at least, near-bottom dives to catch their prey during these short trips. The consequences of this behavioral plasticity in response to variations in sea temperatures and inferred prey availability are discussed, especially with regard to predicted global climate change.
\end{abstract}

Keywords GPS-TDR loggers $\cdot$ Inshore foraging $\cdot$ Benthic diving $\cdot$ Reduced foraging trip length $\cdot$ Sea surface temperature

Klemens Pütz

puetz@antarctic-research.de

1 Antarctic Research Trust, Am Oste-Hamme-Kanal 10, 27432 Bremervörde, Germany

2 Centro Austral de Investigaciones Científicas, Consejo Nacional de Investigaciones Científicas y Técnicas, Bernardo A. Houssay 200, V9410CAB Ushuaia, Tierra del Fuego, Argentina

3 Wildlife Conservation Society, Amenábar 1595, Office 19, C1426AKC CABA, Buenos Aires, Argentina

4 British Antarctic Survey, High Cross, Cambridge CB30ET, UK

5 Antarctic Research Trust, PO Box 685, Stanley FIQQ1ZZ, Falkland Islands

6 Antarctic Research Trust, General-Guisan-Str. 5, 8127 Forch, Switzerland

\section{Introduction}

Environmental changes often negatively affect the persistence of populations or species (Stenseth et al. 2002; Walther et al. 2002). However, all organisms have developed structural (long-term), physiological (medium-term), and behavioral (short-term) adaptations that may help them to survive in a changing environment. Short-term adjustments to changing environmental conditions can occur predominantly through behavioral plasticity, allowing individuals to react promptly to changes in the environment (e.g., Wcislo 1989; Wong and Candolin 2015). The foraging behavior of central place foragers is strongly influenced by prey availability and distribution, and changes in predator behavior over time may reflect modifications in the abundance and/or the distribution of food (e.g., Cairns 1987). For example, temperature differences of even $2{ }^{\circ} \mathrm{C}$ can render the tidal fronts off Patagonia, 
Southwest Atlantic Ocean, less prominent and can lead to massive blooms of gelatinous zooplankton and depress populations of copepods (Sabatini and Martos 2002). This influences the plankton community structure by changing the timing of recruitment and the population growth which in turn affects the trophic chain it generates. Even these "slight" temperature modifications have a bottom-up effect on the entire trophic chain, ultimately affecting top predators' foraging areas and diet (e.g., Garcia-Godos and Goya 2006; Grémillet and Boulinier 2009; Masello et al. 2010; Baylis et al. 2012; Lescroël et al. 2014). Moreover, if these predators feed towards the bottom of the trophic chain, their feeding behavior will be more closely linked and vulnerable to oceanographic conditions affecting primary productivity in their feeding area. Therefore, multi-year studies on the behavior of a predator can elucidate alterations in the marine environment utilized.

Southern Rockhopper penguins (Eudyptes chrysocome, SRP) are meso-predators and distributed throughout the Southern Ocean in the Atlantic, Pacific, and Indian Oceans (Pütz et al. 2013). SRP are currently classified as Vulnerable to extinction (BirdLife International 2017) due to substantial population declines in recent decades over its entire range. These have been linked to several factors such as habitat degradation, chemical pollution, and algal blooms, among others (see review in Pütz et al. 2013; Trathan et al. 2014). In the Southwest Atlantic, there are two main assemblages: Staten Island (ca. 130,000 pairs, Raya Rey et al. 2014) and the Falklands/Malvinas archipelago (ca. 320,000 pairs, Baylis et al. 2013).

SRP feed mainly on low trophic level prey like pelagic crustaceans and, to a lesser degree, small cephalopods and fish (Pütz et al. 2001, 2013). This makes them susceptible to changes in local primary productivity, because their main prey is highly linked to the oceanographic conditions (seasurface temperature (SST), Chlorophyll-a concentration). For example, surface water stratification becomes shallower with increasing SST, thereby providing fewer nutrients for primary productivity compared to a deeper mixed layer (Behrenfeld et al. 2006). However, very deep water mixing may also negatively impact on primary productivity (Smetacek and Passow 1990). Furthermore, plankton species composition is also influenced by changes in SST (Hays et al. 2005). Thus, it can be expected that their preferred foraging areas are also influenced by the prevailing oceanographic conditions (Dehnhard et al. 2013). Studies have shown a link between SST and overwintering survival of SRP at both, the Falklands/Malvinas archipelago and Staten Island (Raya Rey et al. 2007; Dehnhard et al. 2013). In particular, extreme shifts in SST had negative effects on the survival of adults at both sites. In times of accelerated climatic change, modifications in SST fluctuations are predicted which would thus directly affect the survival of this species.
Generally, male SRP return from their winter migration several days earlier than females (Pütz et al. 2013). After egg laying, both partners remain at the nest for some days before the male leaves for 2-4 weeks. When he returns, the female departs to the sea for 1-2 weeks to restore body condition (Pütz et al. 2013). After hatching and during the guard stage, which lasts about 3 weeks, the female alone provisions the offspring with food while the male guards the chicks. Males only leave to regain body condition for some days after the chicks have crèched. Thus, in male SRP, the period at-sea during incubation and is crucial for replenishing body condition and balancing energy demands, because it lies between two extended fasting periods of up to 40 days (Strange 1982; Poisbleau et al. 2008; Pütz et al. 2013). The aim of this study was to (a) investigate the foraging behavior of male SRP in the northeast of East Falkland during the incubation period; (b) compare their behavior amongst study years and with data collected from the same colony in 2000, and (c) determine any potential links between the penguins' behavior and local sea-surface temperatures (SST).

\section{Materials and methods}

Between 2011 and 2014, a total of 62 male SRP from different colonies in Berkeley Sound $\left(51.5^{\circ} \mathrm{S}, 57.9^{\circ} \mathrm{W}\right)$ to the northeast of East Falkland, Falkland/Malvinas Islands (Fig. 1), were externally equipped with either Time-DepthRecorders (TDR) or Global Positioning System-Loggers (GPS) at the onset of the incubation period (for details see Table 1). In brief, penguins clearly associated with a specific nest containing two eggs were visually checked for bill dimensions. Then, the bird with the larger bill was caught, weighed to the nearest $0.1 \mathrm{~kg}$ and bill dimensions measured to verify visual sex determination (Hull 1996; Pütz et al. 2013). Devices were then attached on the mid-line of the back as far distally as possible without impairing the preen gland, using black tape (Tesa, Beiersdorf AG, Hamburg, Germany) according to the method described by Wilson et al. (1997). The whole process took less than 15 min per bird. Recovery of the devices took place during subsequent visits to the colony from 2 weeks after equipment onwards (Table 1). Birds carrying a device were caught and the devices and any remains of the attachment material were removed. To minimize handling times during this critical period, no further body mass weights were taken.

\section{Technical features of the devices used}

All devices were hydrodynamically shaped following the recommendations by Bannasch et al. (1994). The TimeDepth-Recorders (MK9, Wildlife Computers, USA) used were embedded in epoxy resin and weighed, including 
Fig. 1 Location of Berkeley Sound in the northeast of East Falkland, Falkland/Malvinas Islands. The upper panel provides an overview of the Southwest Atlantic, the middle panel shows the Falkland/ Malvinas Islands and the lower panel details bathymetry (modified from British Admiralty Nautical Chart 2550) and study sites within Berkeley Sound. The 30-m depth contours are in red, the 50-m depth contour in dark blue

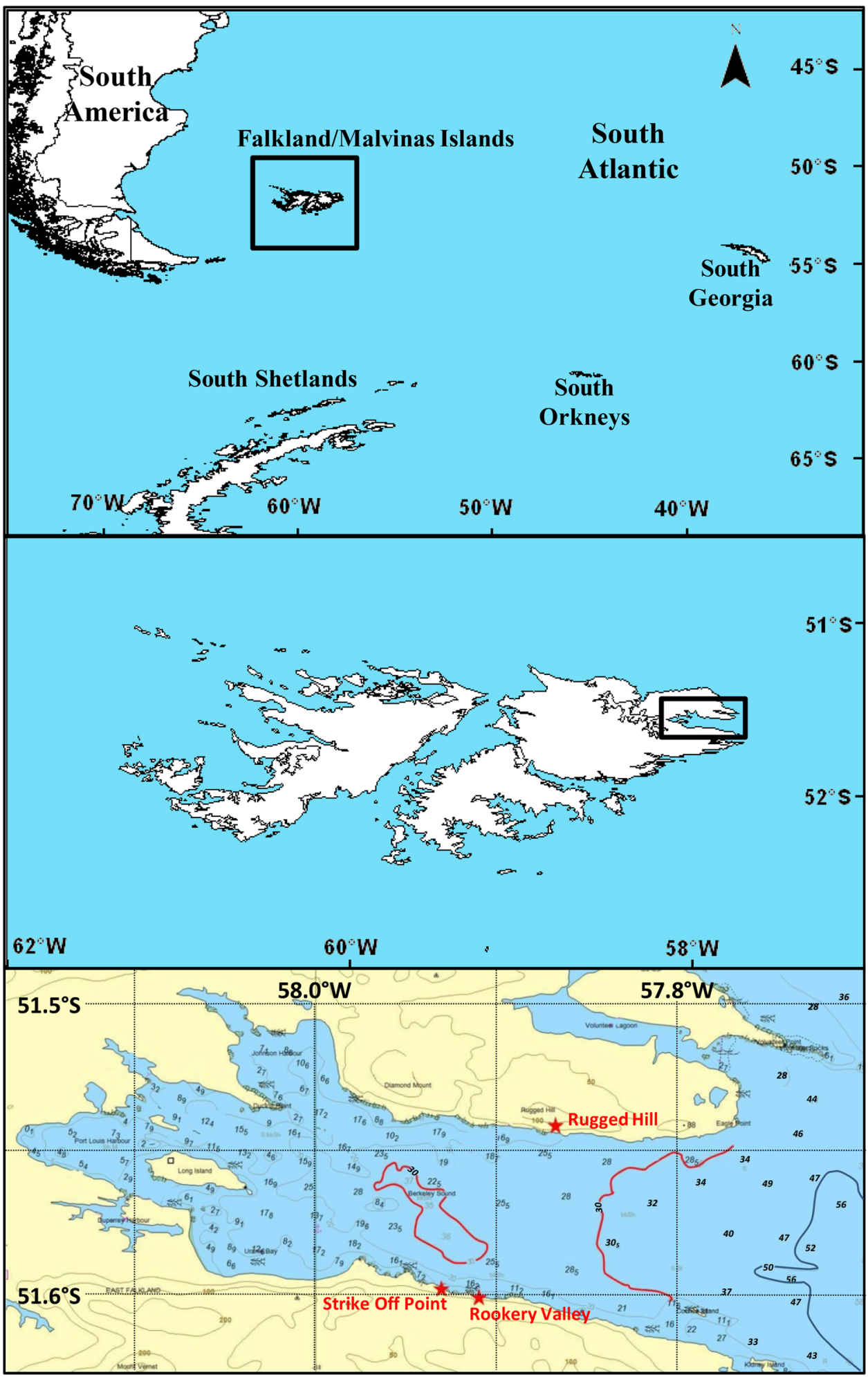

attachment material, less than $50 \mathrm{~g}$, corresponding to ca. $1.3 \%$ of the mean SRP weight of $2.64 \pm 0.23 \mathrm{~kg}$. They had maximum dimensions of $90 \times 21 \times 21 \mathrm{~mm}$ and were programmed with MK9HOST (Wildlife Computers). The TDRs were each equipped with a pressure sensor, a light sensor, and a temperature sensor, programmed to record every $3 \mathrm{~s}$. To optimize energy consumption, a saltwater switch prevented data being recorded while at the surface. The pressure sensor recorded the dive depth between 0 and $350 \mathrm{~m}$, accurate to within $0.5 \mathrm{~m}$ (range 0-20 m), $1 \mathrm{~m}$ (range 
Table 1 Details on study sites, years studied, and devices used on incubating male Southern Rockhopper Penguins, Eudyptes chrysocome, from colonies in Berkeley Sound, East Falkland, Falkland/Malvinas Islands

\begin{tabular}{|c|c|c|c|c|c|c|c|}
\hline Location & Latitude & Longitude & Year & Equipment & Recovery of devices & Birds $(n)$ & Device \\
\hline \multirow[t]{3}{*}{ Rookery Valley } & $51.600^{\circ} \mathrm{S}$ & $57.908^{\circ} \mathrm{W}$ & 2011 & 20-23 Nov & 9-13 Dec & $\begin{array}{l}9 \\
3\end{array}$ & $\begin{array}{l}\text { TDR } \\
\text { Mini-GPS }\end{array}$ \\
\hline & & & 2012 & 11-13 Nov & $25-28 \mathrm{Nov}$ & $\begin{array}{l}9 \\
9\end{array}$ & $\begin{array}{l}\text { TDR } \\
\text { Mini-GPS }\end{array}$ \\
\hline & & & 2013 & 12-14 Nov & 28 Nov-6 Dec & $\begin{array}{l}4 \\
10\end{array}$ & $\begin{array}{l}\text { TDR } \\
\text { Mini-GPS }\end{array}$ \\
\hline Strike Off Point & $51.599^{\circ} \mathrm{S}$ & $57.928^{\circ} \mathrm{W}$ & 2013 & 14-16 Nov & 28 Nov-3 Dec & $\begin{array}{l}5 \\
8\end{array}$ & $\begin{array}{l}\text { TDR } \\
\text { Mini-GPS }\end{array}$ \\
\hline Rugged Hill & $51.543^{\circ} \mathrm{S}$ & $57.852^{\circ} \mathrm{W}$ & 2014 & $20 \mathrm{Nov}$ & $2 \mathrm{Dec}$ & 5 & nanoFix Geo \\
\hline
\end{tabular}

TDR MK9 (Wildlife Computers, USA), Mini-GPS GPS-TDRs (Earth \& Ocean Technologies, Kiel Germany), Fix Geo nanoFix Geo (Pathtrack Ltd, Otley, UK)
20-200 m), and $5 \mathrm{~m}$ (range 200-350 $\mathrm{m}$ ), and the temperature sensor recorded between -40 and $60{ }^{\circ} \mathrm{C}$ with an accuracy of $\pm 0.1^{\circ} \mathrm{C}$. The data from the light sensor were not used in this study.

The GPS-TDRs (Mini-GPS, Earth \& Ocean Technologies, Kiel, Germany) used in 2011-2013 weighed ca. $40 \mathrm{~g}$ including attachment material (corresponding to ca. $1 \%$ of the mean SRP weight) and had maximum dimensions of $57 \times 34 \times 20 \mathrm{~mm}$, excluding a 46-mm-long temperature sensor with a diameter of $4 \mathrm{~mm}$ protruding at the rear end of the devices. They were programmed to record geographical position via GPS at varying intervals depending on the activity of the study birds, which was triggered by the pressure sensor. Additionally, temperature and depth were recorded every $3 \mathrm{~s}$ with an accuracy of $3.5 \mathrm{~cm}$ and $0.005^{\circ} \mathrm{C}$, respectively. The GPS-tags used in 2014 were nanoFix Geo (Pathtrack Ltd, Otley, UK), that measured $55 \times 23 \times 15 \mathrm{~mm}$, excluding the 3-cm-long whip antenna at the rear, and weighed ca. $30 \mathrm{~g}$ (corresponding to ca. $0.8 \%$ of the mean SRP weight). The tags recorded only position and were programmed to collect fixes every $5 \mathrm{~min}$. However, they were equipped with saltwater switches to optimize power consumption and maximize fix acquisition by preventing the search for satellites when underwater but initiating searches as soon as the tag was exposed to air. The tags collected snapshots of the satellite constellation and locations were afterwards processed from online ephemeris data, which considerably reduced the time to obtain fixes and saved battery power.

It is well accepted that the external attachment of devices on free-ranging penguins has the potential to impact on their foraging behavior and breeding success (e.g., Taylor et al. 2001; Wilson and McMahon 2006; Ropert-Coudert et al. 2007), with effects increasing under unfavorable environmental conditions (Ballard et al. 2001). Several measures were taken in this study to reduce the impact of the devices on the penguins' behavior (e.g., hydrodynamics, see above). No logger effect on trip duration, diving behavior, hatching and breeding success or in adult survival was observed in a comparable study on SRP from New Island, Falkland/Malvinas Islands (Ludynia et al. 2012, 2013). Accordingly, in our study, no effect on the immediate egg survival and hatching success was apparent, and breeding success was also not affected which was determined by a comparison of chick survival in our study area compared with a control area in the SRP colony at Rookery Valley (chick survival 24 January 2012 was $69 \%$ in study area versus $70 \%$ in control area). Therefore, we assume that the externally attached devices were not detrimental per se to the penguins and have not essentially altered the birds' behavior. This is further substantiated by studies on the winter dispersal of Magellanic Penguins (Spheniscus magellanicus, Pütz et al. 2000) and SRP (Pütz et al. 2002, 2006a), where also no device effects were apparent over much longer attachment periods.

\section{Positional data analysis}

The positional data obtained were graphically analyzed showing 50 and $95 \%$ kernel distributions of each year combined with the average monthly sea-surface temperatures (SST) at the time (NASA remote sensing MODIS-Aqua SST, $4 \mathrm{~km}$ resolution). In addition, the average SST for the area surrounding the colony in December of each year between 2011 and 2014 was obtained from http://indl.ldeo.colum bia.edu/SOURCES/.NOAA/.NCEP/.EMC/CMB/GLOBA L/.Reyn_SmithOIv2/.monthly/.sst).

Data derived from the integrated temperature sensors of the Mini-GPS in years 2011-2013 were used to create vertical water temperature profiles for selected time periods and locations. Measurements processed derived from the deepest area within Berkeley Sound (c.f. Fig. 1) for all 3 years and from two locations outside Berkeley Sound in 2011. The latter two locations were both situated to the east of the $8^{\circ} \mathrm{C}$ isotherm (c.f. Fig. 2), one $200 \mathrm{~km}$ and the other one $275 \mathrm{~km}$ away from the breeding site, and were chosen because of an accumulation of fixes indicating intense foraging activity. Dive depths associated with a water temperature measurement were averaged over 5-m depth classes to compensate 

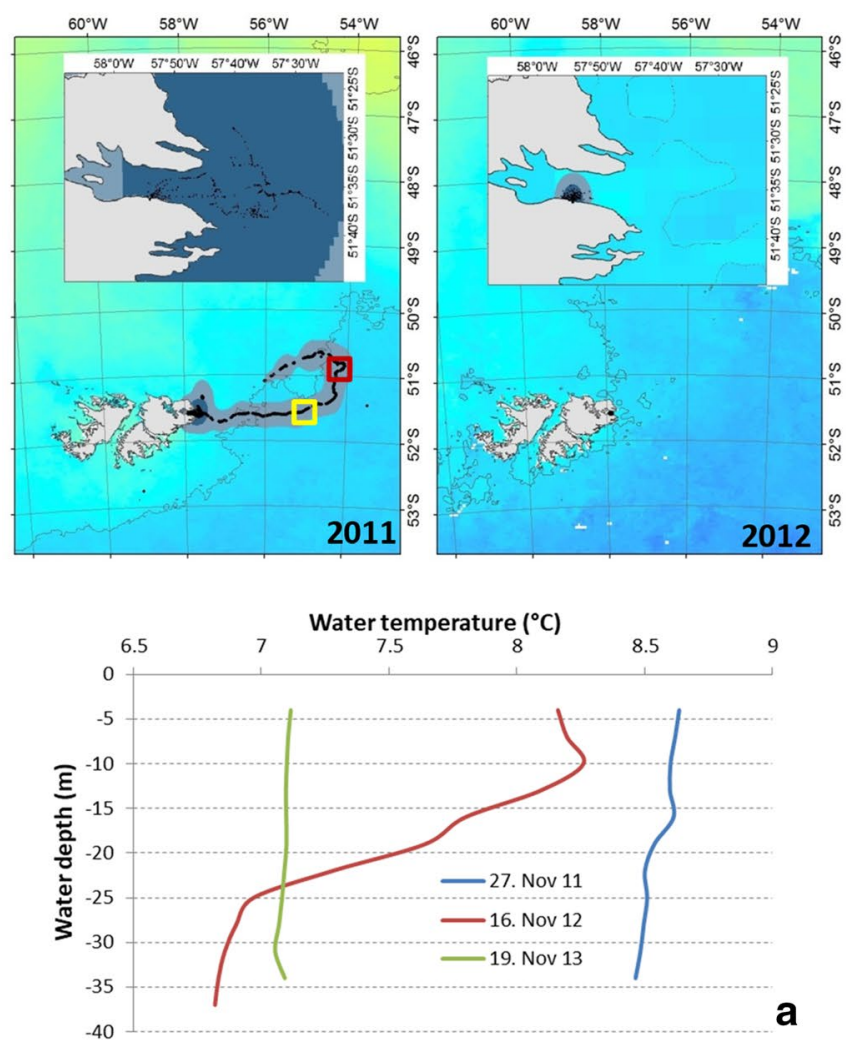

a

Fig. 2 Foraging tracks of male Southern Rockhopper Penguins, Eudyptes chrysocome, from colonies in Berkeley Sound, East Falklands, Falkland/Malvinas Islands, during the incubation period. Insets show 95 and 50\% kernels of the foraging ranges. Shaded background colors provide SST from dark blue (colder) to light green (warmer). Also given is the $8{ }^{\circ} \mathrm{C} \mathrm{SST}$ isotherm in December for the years stud-

for any delay in measurement during descent and ascent. The resulting temperature profiles are only based on the birds that remained in the respective areas on the specific dates given.

\section{Dive data analysis}

Foraging trips were classified as long if they lasted more than $24 \mathrm{~h}$ (=multiple-day trips) and as short (=day trips) if they lasted less than $24 \mathrm{~h}$. Only dives $>5 \mathrm{~m}$ were used in the analysis. Dive data from MK9 were analyzed with INSTRUMENT HELPER (Wildlife Computers); dive data recorded by the Mini-GPS were analyzed using MULTITRACE (Jensen Software Systems, Kiel, Germany). Foraging trip durations were estimated from 2011 to 2013 as the interval between the first and the last dive recorded, and in 2014 as the interval between the first and the last positional fixes at sea. The following parameters were considered in the analysis of the 2011-2013 depth data: Daily foraging time (time difference between the first and the last dive of the day), mean dive depth (m), maximum dive depth (m), dive
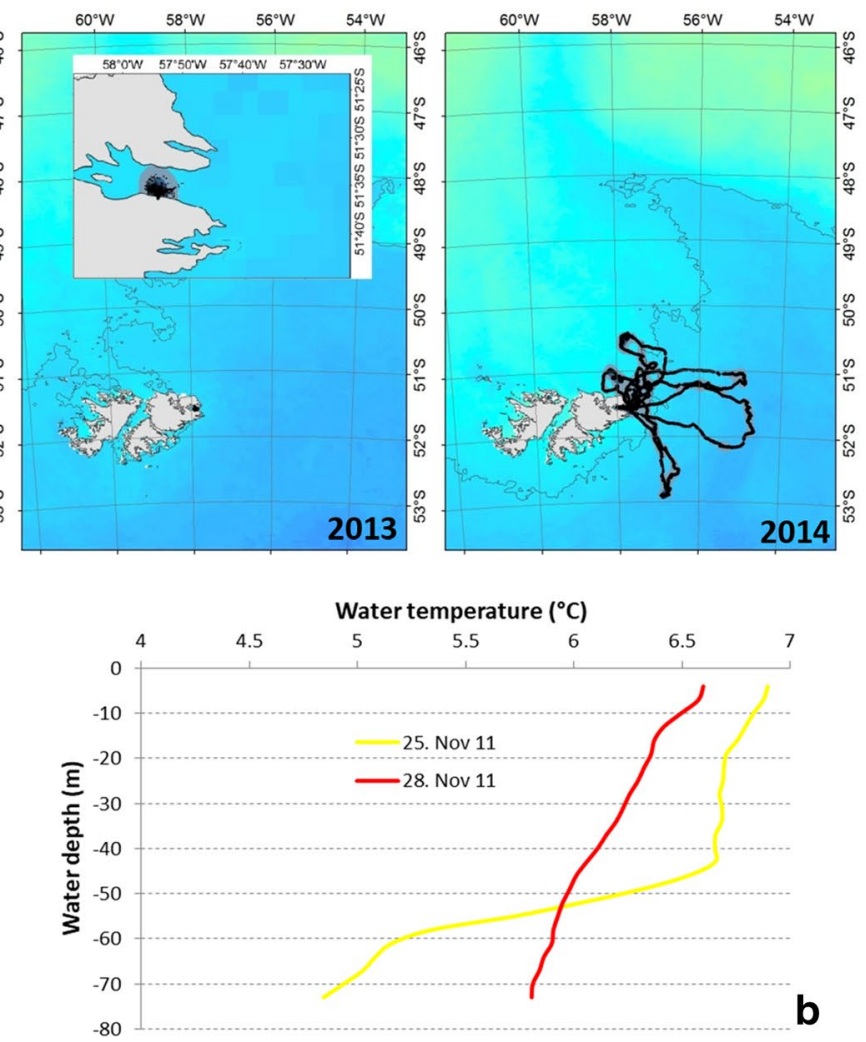

ied. Vertical temperature profiles for water depths between 30 and $37 \mathrm{~m}$ are given for a selected positions and dates in 2011-2013 inside Berkeley Sound and b for 2011 in areas outside Berkeley Sound, indicated by squares in red and yellow. Colors in $b$ mirror the colors of the squares indicating the areas sampled

duration, duration of bottom time (time spent at $80 \%$ of the maximum dive depth), number of wiggles (abrupt changes in dive depth during the bottom time), and vertical velocities during descent and ascent. From these data, diving efficiency (time at bottom/(dive + post-dive duration); Ydenberg and Clark 1989) and foraging efficiency (number of wiggles/min bottom time) were calculated.

GLMMs were generated to compare behaviors amongst years and foraging trip types (long vs. short), with individual as a random effect: $\mathrm{X}$-type (long/short $=$ factor) + year, ran$\mathrm{dom}=\sim 1$ lid and the model is based on restricted maximum likelihood (REML). The percentage of variability explained by the random effect was estimated as the proportion of the total variance included in the intercept of the generated model. Models were compared with individual nested within year as a random factor in order to determine the variability due to year, but given that year was not a significant random effect in any model, year was eliminated from the random effects and only included as a fixed effect. Variables were graphically tested for normality by analyzing the linearity of their qq residual plots. Models were compared with versus 
without the random effect (id) and then with versus without the fixed effects: foraging trip type (short or long) and year (all years with dive depth measurements for individuals breeding within the Berkley Sound, i.e., 2011-2013) with a $\chi^{2}$ estimation. Marginal $\left(R^{2} m\right)$ and conditional $\mathrm{R}^{2}\left(R^{2} c\right)$ of the generated models were also reported to evaluate how well the data adjusted to fixed effects alone $\left(R^{2} m\right)$ or fixed and random effects $\left(R^{2} c\right.$, following Nakagawa and Schielzeth 2013; Nakagawa et al. 2017). All models were generated in $\mathrm{R}$ (version 3.4.1) using packages nlme (Pinheiro et al. 2017), lme4 (Bates et al. 2015), and MuMIn (Barton 2018) and significance was set at $p<0.05$.

Tremblay and Cherel (2000) identified benthic diving in SRP, based on a square-waved shape of the dives, a uniform maximum depth and the lack of deeper dives, all indicators that the sea floor limited the dive depths. In accordance, we visually inspected the foraging trips of all animals equipped with a depth sensor and whose foraging trip positions were located inside Berkeley Sound for indications of a dive depth limitation by the sea floor. However, consistent diving to a certain depth range was rare, which was assumed to be related to the undulating sea bottom ranging in depth from between 0 and $37 \mathrm{~m}$.

Therefore, GLMs were generated with the following structure (X-dive type(benthic/pelagic) as a fixed effect, with two randomly chosen subsamples of 1000 dives to depths between 31 and $37 \mathrm{~m}$ (=maximum depth to be reached in Berkeley Sound) and compared by a $t$ test: one subsample contained pelagic dives performed by birds from the colony at Rookery Valley over the continental shelf in 2000 (data taken from Pütz et al. 2006b), the other consisted of presumed benthic dives performed by SRP from Rookery Valley within Berkeley Sound in 2012-2013 (this study).

\section{Results}

\section{Foraging areas in relation to water temperature}

In 2011, and more noticeably in 2012 and 2013, nearly all individuals performed short daily trips in shallow waters contained within Berkeley Sound (Fig. 2). In 2011, only 2 out of 12 study birds performed exclusively one long trip, six conducted only short trips and the remaining four exhibited a mixture of short and long trips (Table 2). The two exclusive multi-day trips were directed either just beyond the entrance of Berkeley Sound or much further to the east in colder waters well beyond the $8{ }^{\circ} \mathrm{C}$ isotherm, more than $300 \mathrm{~km}$ away from the colony (Fig. 2, Table 2). In 2012 and 2013, all SRP equipped with GPS-Loggers foraged less than $9 \mathrm{~km}$ away from their breeding site within the Berkeley Sound, while the $8^{\circ} \mathrm{C}$ isotherm was either further to the west (2012) or very close (2013) to the breeding site. Accordingly, the proportion of individuals performing multiple-day trips was very low (one bird made a 6-day trip in 2012 and two individuals made two longer trips in 2013), and these individuals also made several single-day trips (Table 2). In 2014, SRP performed multi-day trips, up to $230 \mathrm{~km}$ away from the colony, although 2 birds made 7-day trips in total

Table 2 Foraging parameters of incubating Southern Rockhopper Penguins, Eudyptes chrysocome, from colonies in Berkeley Sound, Falkland/ Malvinas Islands: Rookery Valley in 2011-2013, Strike Off Point in 2013 and Rugged Hill in 2014 ( $s$ short $<24$ h, $l$ long $>24$ h)

\begin{tabular}{|c|c|c|c|c|c|c|}
\hline & Short trips & Long trips & 2011 & 2012 & 2013 & 2014 \\
\hline No. of foraging trips (individuals) & $452(55)$ & $9(9)$ & s: $76(10)$ l: $6\left(6^{\mathrm{a}}\right)$ & s: $145(18) 1: 1\left(1^{b}\right)$ & $\begin{array}{l}\text { s: } 231(27) \\
1: 2\left(2^{b}\right)\end{array}$ & $\begin{array}{l}\text { s: } 7(2) \\
\text { 1: } 5\left(5^{c}\right)\end{array}$ \\
\hline Foraging trip duration (days) & $0.4 \pm 0.1$ & $8.1 \pm 2.1$ & $\begin{array}{l}\text { s: } 0.4 \pm 0.1 \\
\text { 1: } 6.6 \pm 2.8\end{array}$ & $\begin{array}{l}\text { s } 0.4 \pm 0.1 \\
1: 6.5\end{array}$ & $\begin{array}{l}\text { s: } 0.3 \pm 0.1 \\
\text { l: } 1.3\end{array}$ & $\begin{array}{l}\text { s: } 0.5 \pm 0.1 \\
\text { 1: } 8.7 \pm 1.7\end{array}$ \\
\hline Max distance to colony (km) & & & $\begin{array}{l}\text { s: } 40 \\
\text { 1: } 310\end{array}$ & 7 & 9 & $\begin{array}{l}\text { s: } 12 \\
\text { l: } 230\end{array}$ \\
\hline Daily foraging duration (h) & $7.6 \pm 3.1$ & $16.6 \pm 3.7$ & $10.7 \pm 6.0$ & $7.7 \pm 3.3$ & $8.1 \pm 3.3$ & \\
\hline Mean dive depth (m) & $19 \pm 5$ & $24 \pm 9$ & $19 \pm 8$ & $17 \pm 5$ & $22 \pm 4$ & \\
\hline Max dive depth (m) & $31 \pm 6$ & $51 \pm 14$ & $37 \pm 16$ & $29 \pm 8$ & $34 \pm 5$ & \\
\hline Diving efficiency & $0.38 \pm 0.06$ & $0.47 \pm 0.14$ & $0.44 \pm 0.11$ & $0.40 \pm 0.06$ & $0.36 \pm 0.05$ & \\
\hline Foraging efficiency & $3.5 \pm 1.1$ & $2.4 \pm 0.9$ & $2.9 \pm 1.0$ & $4.1 \pm 1.2$ & $3.3 \pm 1.0$ & \\
\hline
\end{tabular}

Calculation of foraging trip duration is based on the time difference between the first and last dive in birds studied between 2011 and 2013 and between the first and last position at sea in birds studied in 2014. Values are given as mean \pm SD

${ }^{a}$ Four out of six individuals performed both, short and long trips

${ }^{\mathrm{b}}$ These individuals also preformed short trips

${ }^{\mathrm{c}}$ Two of these individuals also performed short trips 
before starting their multiple-day trip. Also, in 2014 the $8{ }^{\circ} \mathrm{C}$ SST isotherm was located further to the east (Fig. 2).

Taking into account the vertical temperature profiles, which are based on recordings of the temperature sensors integrated into the GPS-loggers, there were also pronounced differences between 2011 and 2013 within the deepest foraging area in Berkeley Sound, where water depths exceed $30 \mathrm{~m}$ (Fig. 1). In 2011, the water body was well mixed with a temperature of $>8.5^{\circ} \mathrm{C}$ (Fig. 2). A well-mixed water body was also apparent in 2013 , but the temperature was lower at between 7.1 and $7.2^{\circ} \mathrm{C}$. In contrast, in 2012 the water exhibited a pronounced stratification, with temperatures above $8^{\circ} \mathrm{C}$ in the upper $10 \mathrm{~m}$, a temperature decrease between 10 and $25 \mathrm{~m}$ down to $6.9^{\circ} \mathrm{C}$, and a mixed water body onwards to the sea floor with temperatures of $6.8-6.9^{\circ} \mathrm{C}$.

For spatial comparison, the two areas sampled in 2011 outside Berkeley Sound, indicated by squares in Fig. 2, were colder but showed the same vertical mixing pattern, at least in the upper $40 \mathrm{~m}$. The area just off the mouth of Berkeley Sound, sampled on 25 November 2011, exhibited a stratified water mass with a water temperature $>6.5^{\circ} \mathrm{C}$ down to $40 \mathrm{~m}$, followed by a decrease in temperature to $5{ }^{\circ} \mathrm{C}$ over the next $20 \mathrm{~m}$ and a further, but less pronounced decrease between 60 and $75 \mathrm{~m}$. In contrast, 3 days later, on 28 November 2011, and further away from Berkeley Sound, water temperature decreased continuously from $6.6{ }^{\circ} \mathrm{C}$ near the surface to just above $5.8^{\circ} \mathrm{C}$ at a water depth of $70 \mathrm{~m}$.

\section{Diving behavior}

For years 2011-2013, the calculation of specific foraging characteristics allowed the comparison of selected dive parameters (Tables 2 and 3). Daily foraging duration was more than twice as high in long compared with short trips. However, daily foraging duration differed only marginally amongst years (trip type: $\chi^{2}=208.3$, $p<0.01$ and year: $\chi^{2}=3.7, p=0.05$; random effects of individual accounted for $32 \%$ of the variability in the data, $\left.R^{2} m=0.47-R^{2} c=0.57\right)$. The mean and maximum dive depths reached by individuals were again higher during long trips, and also differed amongst years (mean depth: trip type: $\chi^{2}=25.7, p<0.01$ and year: $\chi^{2}=27.8, p<0.01$; random effects (37\% of variability, $R^{2} m=0.12-R^{2} c=0.38$ ), and maximum depth: trip type: $\chi^{2}=130.1, p<0.01$ and year: $\chi^{2}=19.4, p<0.01$; random effects $(36 \%$ of variability, $R^{2} m=0.34-R^{2} c=0.53$ ). Dive efficiency (time at bottom/[dive + post-dive duration]) differed amongst years but not between foraging trip types (trip type: $\chi^{2}=0.2$, $p=0.66$ and year: $\chi^{2}=5.5, p=0.02$; identity explained $57 \%$ of variability $\left.R^{2} m=0.18-R^{2} c=0.69\right)$. Foraging efficiency (number of wiggles/bottom time) also differed amongst years but also between foraging trip types, being higher in one-day trips than in multi-day trips, particularly in 2012 (trip type: $\chi^{2}=12.0, p \leq 0.01$ and year: $\chi^{2}=8.2, p<0.01$; identity explained $53 \%$ of the variability, $R^{2} m=0.04-R^{2} c=0.62$, see Table 3 ).

From 2011 to 2013, many birds engaged in day trips which were directed to shallow waters depths $<37 \mathrm{~m}$ within the Sound, with maximum dive depths often coinciding with the maximum water depths (Fig. 1). The subsamples of benthic (years 2012 and 2013) and pelagic (year 2000, data obtained in the colony at Rookery Valley, taken from Pütz et al. 2006b) dives revealed significant differences with regard to the performance of the dives (Fig. 3, Table 4). In comparison, total dive duration and post-dive interval were significantly shorter in benthic dives. When compared to pelagic dives, benthic dives showed similar bottom time, more wiggles and faster descent and ascent speeds. Accordingly, the calculated diving and foraging efficiencies were both higher in benthic foraging SRPs.

Table $3 \chi^{2}$ test and statistical significance of fixed (type and year) and random effects (ID and ID nested within year) of GLMMs of foraging parameters of male Southern Rockhopper Penguins, Eudyptes chryso-

come, from the colony at Rookery Valley, Berkeley Sound, Falkland/ Malvinas Islands, in 2011-2013

\begin{tabular}{|c|c|c|c|c|}
\hline & \multicolumn{2}{|l|}{ Fixed effects } & \multicolumn{2}{|l|}{ Random effects } \\
\hline & Type (long vs. short) & Year (2011-2013) & ID vs. ID (year) & ID vs. no random \\
\hline Daily foraging duration & $\begin{array}{l}\chi^{2}=208.3 \\
p<0.01\end{array}$ & $\begin{array}{l}\chi^{2}=3.7 \\
p=0.05\end{array}$ & $\begin{array}{l}\chi^{2} \approx 0 \\
p=1\end{array}$ & $\begin{array}{l}\chi^{2}=34.5 ; p<0.01 \\
32 \% \text { of variability explained }\end{array}$ \\
\hline Mean dive depth & $\begin{array}{l}\chi^{2}=25.7 \\
p<0.01\end{array}$ & $\begin{array}{l}\chi^{2}=27.8 \\
p<0.01\end{array}$ & $\begin{array}{l}\chi^{2} \approx 0 \\
p=1\end{array}$ & $\begin{array}{l}\chi^{2}=67.6 ; p<0.01 \\
37 \% \text { of variability explained }\end{array}$ \\
\hline Maximum dive depth & $\begin{array}{l}\chi^{2}=130.1 \\
p<0.01\end{array}$ & $\begin{array}{l}\chi^{2}=19.4 \\
p<0.01\end{array}$ & $\begin{array}{l}\chi^{2} \approx 0 \\
p=1\end{array}$ & $\begin{array}{l}\chi^{2}=60.4 ; p<0.01 \\
36 \% \text { of variability explained }\end{array}$ \\
\hline Diving efficiency & $\begin{array}{l}\chi^{2}=0.2 \\
p=0.66\end{array}$ & $\begin{array}{l}\chi^{2}=5.5 \\
p=0.02\end{array}$ & $\begin{array}{l}\chi^{2} \approx 0 \\
p=1\end{array}$ & $\begin{array}{l}\chi^{2}=282.8 ; p<0.01 \\
57 \% \text { of variability explained }\end{array}$ \\
\hline Foraging efficiency & $\begin{array}{l}\chi^{2}=12.0 \\
p<0.01\end{array}$ & $\begin{array}{l}\chi^{2}=8.2 \\
p<0.01\end{array}$ & $\begin{array}{l}\chi^{2} \approx 0 \\
p=1\end{array}$ & $\begin{array}{l}\chi^{2}=282.8 ; p<0.01 \\
53 \% \text { of variability explained }\end{array}$ \\
\hline
\end{tabular}


Fig. 3 Depth profile of a male Southern Rockhopper Penguin, Eudyptes chrysocome, from the colony at Rookery Valley in Berkeley Sound, East Falklands, Falkland/Malvinas Islands, during incubation in 2013. At the top, the whole dive profile is shown; red areas mark daily dive bouts (middle) and further details (bottom). Benthic dives are only identifiable in the right hand graphs. For details see text

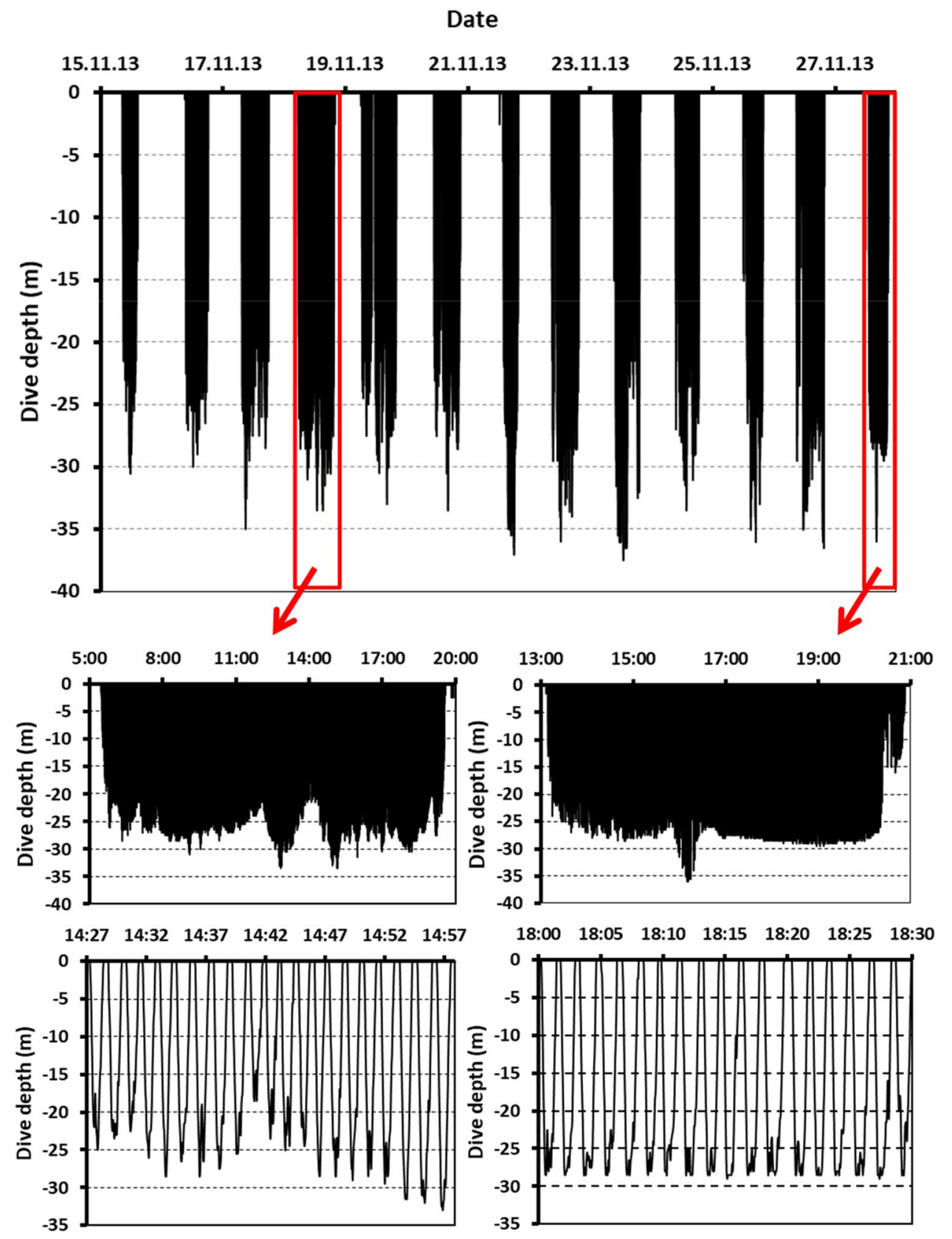

\section{Discussion}

\section{Foraging trip duration}

The breeding cycle of SRP is well established throughout its distributional range (Williams 1995; Pütz et al. 2013). Generally, after the second (B-) egg has been laid, partners share incubation duties for some days. Then, males depart for a foraging trip lasting between several days up to 3 weeks before returning to the nest to exchange incubation duties, thereby enabling the female to perform a multi-day foraging trip before the chicks hatch after a total incubation period of between 32 and 34 days. However, the exact timings of the three periods-shared incubation, long male, and long female foraging trip — can vary annually and spatially. For example, on Crozet males depart on average 11.7 days after the B-egg has been laid (Williams 1995) and on Macquarie it takes on average 10 days (Hull et al. 2004). A comparison of the foraging trip durations of SRP from breeding sites in the Southwest Atlantic is shown in Table 5. In the Falkland/ Malvinas Islands, eggs are laid in early November and most males leave by mid-November to perform their long incubation trip (Pütz et al. 2003, 2006b; Ludynia et al. 2013). However, in our study, in 2011-2013 SRP from the colonies in Berkeley Sound performed almost exclusively short day trips, during which they foraged close to the breeding site 
Table 4 Statistical comparison ( $t$ test of a GLM) of two randomly selected subsamples of benthic $(2012-2013, n=1000)$ and pelagic dives (2000, $n=1000$; data from Pütz et al. 2006b) between 30 and $37 \mathrm{~m}$ for selected diving parameters of male Southern Rockhopper Penguins, Eudyptes chrysocome, from Berkeley Sound, Falkland/ Malvinas Islands

\begin{tabular}{lcccc}
\hline Variable & Benthic & Pelagic & $t$ & $p$ \\
\hline Dive duration (s) & $76.7 \pm 9.5$ & $91.7 \pm 11.7$ & 31.5 & $<0.0001$ \\
Post-dive interval (s) & $20.4 \pm 6.0$ & $35.5 \pm 15.0$ & 32.2 & $<0.0001$ \\
Bottom time (s) & $35.9 \pm 11.3$ & $35.5 \pm 12.8$ & 0.8 & 0.43 \\
No. of wiggles (n) & $1.9 \pm 1.8$ & $1.0 \pm 1.0$ & 13.3 & $<0.0001$ \\
Descent rate (m/s) & $1.36 \pm 0.18$ & $1.25 \pm 0.26$ & 10.8 & $<0.0001$ \\
Foraging efficiency & $2.86 \pm 2.69$ & $1.46 \pm 1.41$ & 17.7 & $<0.0001$ \\
\hline
\end{tabular}

Means are given \pm SD

and frequently returned to their partner (452 short versus 9 long trips, c.f. Table 2). This is even more surprising as in 2000 the birds from Rookery Valley still conformed to the established schedule (Pütz et al. 2006b). In 2014, birds from the Rugged Hill again returned to the established behavioral pattern and performed multi-day trips, although they still lasted less long than in conspecifics from other breeding sites before 2011 and were in some birds still preceded by a series of short trips. How can these behavioral changes be explained?

Several studies on seabirds have shown that mass gain at sea is positively related to foraging trip duration (e.g., Weimerskirch 1995; Barlow and Croxall 2002; Emmerson et al. 2011), because foraging trip lengths may vary depending on food availability and foraging success (e.g., Cairns
1987; Williams 1995). The long foraging trip by male SRP during incubation occurs in the middle of two extended fasting periods of up to ca. 40 days (Strange 1982; Poisbleau et al. 2008; Pütz et al. 2013). Birds are thus not only obliged to gain enough food to refill their empty energy stores but also to build up enough energy reserves to sustain them during the following fasting period. It is therefore important for male SRP to have a reliable foraging ground with sufficient food supply during their time at sea (Ludynia et al. 2013) and it appears that usually male SRP perform long trips owing to their need to restore their body mass. For example, during the incubation period, male SRP from Isla de los Estados foraged in deep waters extending south and east from the breeding site for 13-19 days (Pütz et al. 2006b; Raya Rey et al. 2007). Breeding birds from New Island in the southwest of the Falkland/Malvinas Islands foraged to the west, sometimes as far as the eastern entrance of the Magellan Strait (Boersma et al. 2002; Ludynia et al. 2013). Also, male SRP from the Seal Bay colony to the north of East Falkland at a linear distance of $25 \mathrm{~km}$ from the study colonies in Berkeley Sound foraged to the north of the colony at the Patagonian Shelf slope (Pütz et al. 2003). In all cases, the foraging ranges exceeded $100 \mathrm{~km}$ and included waters deeper than $200 \mathrm{~m}$.

Given this common behavior displayed by birds from various colonies, we suggest that the unusual behavior observed in our study in years 2011-2013 was triggered by favorable food conditions just off the colony, enabling SRP to meet their elevated energy demand while performing day trips and returning to the incubating partner on a daily basis. These short trips have the advantage that no energy is wasted to

Table 5 Comparison of foraging trip durations of incubating male Southern Rockhopper Penguins, Eudyptes chrysocome, at various breeding sites in the Southwest Atlantic

\begin{tabular}{|c|c|c|c|c|c|c|c|}
\hline Location & Year & Birds $(n)$ & Onset & Duration (days) & End & Range (days) & Source \\
\hline Staten Island & 2001-2002 & 10 & 2-6 Nov & 22.2 & & $17-33$ & Pütz et al. (2006a, b) \\
\hline New Island & 1998-1999 & 12 & & $>3$ & & & Boersma et al. (2002) \\
\hline Seal Bay & 1998 & 4 & $8-16$ Nov & 18.5 & & $11-24$ & Pütz et al. (2003) \\
\hline Seal Bay & 1999 & 5 & $17-26 \mathrm{Nov}$ & 20.0 & & $12-27$ & Pütz et al. (2003) \\
\hline Rookery Valley & 2000 & 10 & 21-23 Nov & 13.3 & & $9-24$ & Pütz et al. (2006a, b) \\
\hline New Island & 2009 & $6^{\mathrm{a}}$ & 9 Nov (mean) & 14.2 & 25 Nov (mean) & $12-18$ & Ludynia et al. (2013) \\
\hline New Island & 2010 & 6 & 20 Nov (mean) & 15.5 & 5 Dec (mean) & $10-19$ & Ludynia et al. (2013) \\
\hline Rookery Valley & 2011 & $12^{\mathrm{b}}$ & 20-23 Nov & 0.8 & $29 \mathrm{Nov}-12 \mathrm{Dec}$ & $1-11$ & This study \\
\hline Rookery Valley & 2012 & $18^{\mathrm{c}}$ & 11-13 Nov & 0.3 & $23-26 \mathrm{Nov}$ & $1-6$ & This study \\
\hline Rookery Valley & 2013 & $14^{\mathrm{c}}$ & 10-15 Nov & 0.3 & 28 Nov-3 Dec & $1-2$ & This study \\
\hline Strike Off Point & 2013 & $13^{\mathrm{c}}$ & 14-16 Nov & 0.4 & 28 Nov-1 Dec & $1-2$ & This study \\
\hline Rugged Hill & 2014 & $5^{\mathrm{d}}$ & 20-24 Nov & 4.6 & 22 Nov-6 Dec & $1-12$ & This study \\
\hline
\end{tabular}

${ }^{\mathrm{a}} 4$ birds also made 9 short trips

$\mathrm{b}_{4}$ birds also made short trips and 6 birds only made short trips

${ }^{\mathrm{c}} 1$ bird also made a long trip, all the rest were short trips

${ }^{\mathrm{d}} 2$ birds also made 7 short trips but long trips started 22 and 24 Nov, respectively 
travel to remote foraging grounds, and to have to rest at sea overnight when light intensity is too low to forage efficiently (Wilson et al. 1993), which is energetically more demanding than resting ashore due to the higher thermal conductivity of water compared to air and the need to maintain body temperature (Froget et al. 2004; Green et al. 2009). Furthermore, the increased presence of two birds at the nest site may result in an enhanced nest defense from predators or conspecifics (Morrison et al. 2017). Thus, these factors may not only considerably reduce the elevated energy demand during that critical period, but may also result in a higher hatching success.

\section{Trip duration and SST}

Changes in SST are known to influence food availability by affecting primary productivity, which in turn determines prey abundance (Richardson and Schoeman 2004; Frederiksen et al. 2006) and species composition (Scheffer and Carpenter 2003; Hays et al. 2005). Accordingly, links between oceanographic variability and foraging success have been shown for a number of higher trophic level consumers, in particular seabirds and marine mammals (e.g., Bost et al. 2009; Forcada and Trathan 2009; Thorne et al. 2015). In our study, a decreased SST resulted in a considerably reduced foraging trip duration and foraging range. The same phenomenon, to a lesser extent, has been observed in SRP during the chick-rearing period (Dehnhard et al. 2016). Furthermore, it could be shown that lower SST increased not only the likelihood of SRP individual survival over the winter months (Raya Rey et al. 2007; Dehnhard et al. 2013) but also individual body mass at the onset of the reproduction period (Dehnhard et al. 2015a). In turn, the latter resulted in earlier egg-laying dates with increased clutch masses (Dehnhard et al. 2015b) and an overall higher breeding success (Crawford et al. 2008).

However, over the past decades, the global Rockhopper Penguin population has significantly decreased (Pütz et al. 2013), with declines related to both decreasing (Guinard et al. 1998) or increasing SST (Cunningham and Moors 1994; Thompson and Sagar 2002; Hilton et al. 2006; Raya Rey et al. 2007), indicating that these birds are highly sensitive to changes in SST in either direction. As a specific example, in 2016, a mass mortality occurred in SRP in the Falklands during the molting period, which was attributed to pre-molt starvation following much colder than usual sea temperatures, which in turn was assumed to have resulted in reduced food availability (Crofts and Stanworth 2017; Morgenthaler et al. 2018). Thus, in SRP, environmental differences may be buffered only to a certain extent by behavioral plasticity.

A generally increasing SST in the Southern Ocean, as predicted by climate change scenarios, may therefore have a large influence on the distance to reliable foraging grounds and subsequently impact on the species' persistence. For example, in King Penguins Aptenodytes patagonicus climate change was predicted to result in increasing distances to the preferred foraging grounds at the Antarctic Polar Frontal Zone (APFZ), which in turn will have negative consequences on breeding success and recruitment (Péron et al. 2012).

\section{D temperature profiles}

While the SST derived from satellite data may provide a reasonable proxy for differences in the behavior of marine air-breathing vertebrates, further clues can be derived from vertical temperature profiles collected by the study animals in situ (e.g., Boehme et al. 2008; Sala et al. 2017). In our study, pronounced differences could be found with regard to the overall temperature of the whole water body as well as its stratification. This was particularly evident in the inshore waters of Berkeley Sound, where temperature differed by $1.5^{\circ} \mathrm{C}$ in a well-mixed water body when comparing 2011 and 2013. On the contrary, in 2012 the water body was highly stratified with a pronounced thermocline. This scenario may have been mirrored in the foraging behavior of the SRP, because in 2011 in relatively warm, well-mixed waters a higher number of multiple-day trips was observed (7.8\%) when compared to $2012(0.7 \%)$ and 2013 (0.9\%; c.f. Table 3). Also, in 2011 in colder waters to the east of the $8^{\circ} \mathrm{SST}$ thermocline, differences in the water bodies were apparent, with a stratification in the area visited by the study bird on 25 November, whereas the water to the northeast was colder but less stratified, potentially impacting on prey availability. In addition to the above-mentioned assumption that SRP benefit from slightly colder than usual conditions with regard to SST, the occurrence of a stratified water body may further enhance their foraging success. Thus, vertical temperature profiles can provide further clues, beyond 2D satellite-derived SST data, about specific behaviors displayed by penguins (e.g., Sala et al. 2017), but also other seabirds and marine mammals in general (Boehme et al. 2008; Treasure et al. 2017). In any case, much more research is needed on the relationship between ocean temperatures in three dimensions, food availability, and behavioral plasticity of predators to further elucidate potential climate change scenarios throughout the food web.

\section{Diving behavior}

The assumed profitable food availability is also manifested in the diving behavior of SRP in 2011-2013. While the mean dive depth, which in turn determines dive duration and other diving parameters (Wilson 1995), was comparable to conspecifics from the Falkland Islands in 2000 and from 
Staten Island in 2001 and 2002 (Pütz et al. 2006b), the diving efficiency was much higher. However, while this could be a consequence of the different thresholds for analysis ( $5 \mathrm{~m}$ in this study compare to $3 \mathrm{~m}$ in Pütz et al. 2006b), it may also indicate a substantial amount of beneficial benthic or near-bottom diving, which is further substantiated by the comparatively high diving efficiency.

Benthic or near-bottom diving has already been described for Chinstrap Pygoscelis antarctica (Takahashi et al. 2003), Gentoo P. papua (Xavier et al. 2017), Yellow-eyed Megadyptes antipodes (Mattern et al. 2007), and Northern Rockhopper Penguins Eudyptes moseleyi (Tremblay and Cherel 2000). According to Tremblay and Cherel (2000), an indication for benthic diving is a consistent, uniform dive depth over time, with the lack of deeper dives. This was also apparent in SRP from New Island, West Falklands, and the serial dives within a certain depth range were subsequently attributed to benthic diving (Ludynia et al. 2013). However, although this pattern was less obvious in our data set, which is assumed to be due to heterogeneity in the water depths within Berkeley Sound (c.f. Fig. 1), we strongly believe that SRPs in Berkeley Sound foraged frequently at or, at least, near the bottom, because dive depths were often similar to that of the maximum water depth. Furthermore, our subsamples of randomly selected dives to the same water depth range within and outside Berkeley Sound revealed significant differences in the diving performance. Benthic dives were significantly shorter than pelagic dives, but included a comparable bottom time and a shorter post-dive interval, which consequently resulted in a higher diving efficiency. In contrast, for Northern Rockhopper Penguins, a closely related species, benthic dives lasted longer, included a longer bottom time and had longer post-dive intervals than pelagic dives, but still exhibited a higher diving efficiency (Tremblay and Cherel 2000). One explanation for these differences could be the fact that benthic dives in the study of Tremblay and Cherel (2000) were on average $8.6 \mathrm{~m}$ deeper than pelagic dives, whereas in our study benthic and pelagic dives were compared within the same depth range, with subsample means differing by less than $1 \mathrm{~m}$. In both studies, vertical velocities displayed during descent and ascent phases were higher in benthic dives than in pelagic dives, which can be explained by the fact that birds proceed to the sea bottom without searching for prey in the water column, thereby minimizing transit and maximizing bottom times. In penguins, dive duration and vertical velocities, among others, are strongly related to the maximum dive depth achieved (e.g., Wilson 1995). However, these parameters may differ depending on the maximization of bottom time, which is favorable in both, benthic and pelagic dives, when prey is distributed at a certain depth range only. In King Penguins, for example, it could be shown that these parameters differ between different dive shapes, with $\mathrm{W}$-shaped dives, assumed to be performed when prey is located at a certain depth range only, having higher vertical velocities than $\mathrm{U}$-shaped dives, where prey is supposed to be distributed more evenly in the water column (Pütz and Cherel 2005). All these parameters also influence the calculation of diving efficiency and foraging success, which subsequently were significantly higher in benthic dives. It thus appears that SRP maximized their efficiency in benthic dives by higher descent and ascent rates while bottom times were comparable, resulting in shorter total dive durations. By applying this strategy, about $37 \%$ of each dive cycle (=dive duration plus post-dive interval) were spent at the bottom, whereas in pelagic dives the bottom time accounted for only $28 \%$ of each dive.

To summarize, male SRP in our study showed significant behavioral plasticity. Despite being previously recognized as multiple-day foragers during incubation, they obviously have the capability to adapt to favorable food conditions under changing marine regimes, resulting not only in shorter foraging trip durations, but also in a complete change of behavior as birds returned regularly to their nest site in the evening. Furthermore, there appeared to be a substantial amount of benthic diving involved in short trips. While less favorable conditions have been reported to increase foraging ranges and success and ultimately negatively influenced chick growth, this is the first time that a substantial behavioral change following environmental changes actually has the potential to improve reproductive conditions. The importance of such behavioral flexibility for the survival of individual species is evident in African Penguin Spheniscus demersus fledglings that travel to places where food once has been but is no longer present (Sherley et al. 2017), contributing to an already decreasing population. However, this behavior may be unique to genetically determined juveniles who have not yet built up enough experience to locate sufficient food resources, whereas growing experience in aging birds may fine-tune the genetically predetermined behavior. For example, in King Penguins, it could be shown that fledglings from different breeding sites explored the same food resources, whereas adults showed significant differences in their foraging preferences (Pütz et al. 2014).

Acknowledgements The Antarctic Research Trust is grateful for financial support from the following individuals and organizations: Susanne \& Roland Amstutz, Peter Anhäuser, Dr. Martin Bauert/Zoo Zürich (Switzerland), Ruedi Bless/Globetrotter Tours AG (Switzerland), Doris Brennwald, Carmen \& Peter Einstein, Tina \& Paul Falke, Dr. Peter Galbusera/Royal Zoological Society of Antwerp (Belgium), Prof. Rudolf Glockshuber, Beatrix \& Walter Grimm, Dr. Otto Haab, Rita \& Guido Heule, Jacqueline \& Peter Hilpert, Claudine \& Prof. Jean-Pierre Joho, Monika \& Martin Kammerer, Stephanie Keller, Hugo Mathys, Esthi \& Ueli Regli, Rheinfinanz AG (Switzerland), Maja Rüegger-Pfister, Brigitta \& Urs Scharpf, Kathrin Schmidt, Hans Ulrich Schneebeli, Angela Schulthess, Inge \& Albert Sicker, Carine \& Hans Steiger, Barbara Trentini/Stiftung Ormella (Switzerland), Dr. Hans Dieter Vontobel/ 
Vontobel Stiftung (Switzerland), Hedel \& Harald Voss, Anja Weber, Yolanda Wintsch, Zoo-Verein Wuppertal (Germany). The assistance of Gerhard Meyer, Kalinka Rexer-Huber, and Ken Passfield during field work is gratefully acknowledged. Many thanks are also due to Lisa and Adrian Lowe for supporting this study in many different ways and for providing access to the penguin colony at Rookery Valley. Glenda and Neil Watson provided access to the penguin colony at Strike Off Point. Thanks are also due to Nina Dehnhard and two anonymous reviewers for their comments which greatly improved the manuscript.

\section{Compliance with ethical standards}

Conflict of interest The authors declare that no conflict of interest exists.

Ethical approval This study was approved by the Environmental Planning Department of the Falkland Island Government under Section 9 of the Conservation of Wildlife and Nature Ordinance 1999 (FIG Research License R16/2011-13). All applicable international, national, and institutional guidelines for the care and use of animals were followed. All procedures performed in studies involving animals were in accordance with the ethical standards of the institution or practice at which the studies were conducted.

Open Access This article is distributed under the terms of the Creative Commons Attribution 4.0 International License (http://creativeco mmons.org/licenses/by/4.0/), which permits unrestricted use, distribution, and reproduction in any medium, provided you give appropriate credit to the original author(s) and the source, provide a link to the Creative Commons license, and indicate if changes were made.

\section{References}

Ballard G, Ainley DG, Ribic CA, Barton KR (2001) Effect of instrument attachment and other factors on foraging trip duration and nesting success of Adélie penguins. Condor 103:481-490

Bannasch R, Wilson RP, Culik BM (1994) Hydrodynamic aspects of design and attachment of a back-mounted device in penguins. $\mathrm{J}$ Exp Biol 194:83-96

Barlow KE, Croxall JP (2002) Seasonal and interannual variation in foraging range and habitat of macaroni penguins Eudyptes chrysolophus at South Georgia. Mar Ecol Prog Ser 232:291-304

Barton K (2018) MuMIn: multi-model interference. R package version 1.40.4. https://CRAN.R-project.org/package $=$ MuMIn

Bates D, Maechler M, Bolker B, Walker S (2015) Fitting linear mixedeffects models using LME4. J Stat Softw 67:1-48

Baylis AMM, Zuur AF, Brickle P, Pistorius PA (2012) Climate as a driver of population variability in breeding Gentoo Penguins Pygoscelis papua at the Falkland Islands. Ibis 154:30-41

Baylis AMM, Wolfaardt AC, Crofts S, Pistorius PA, Ratcliffe N (2013) Increasing trend in the number of Southern Rockhopper Penguins (Eudyptes c. chrysocome) breeding at the Falkland Islands. Polar Biol 36:1007-1018

Behrenfeld MJ, O'Malley RT, Siegel DA, McClain CR, Sarmiento JL, Feldman GC, Milligan AJ, Falkowski PG, Letelier RM, Boss ES (2006) Climate-driven trends in contemporary ocean productivity. Nature 444:752-755

BirdLife International (2017) Eudyptes chrysocome. (amended version published in 2016) The IUCN red list of threatened species 2017. https://doi.org/10.2305/iucn.uk.2017-1.rlts.t22735250a 111155869.en
Boehme L, Thorpe SE, Biuw M, Fedak M, Meredith MP (2008) Monitoring Drake Passage with elephant seals: frontal structures and snapshots of transport. Limnol Oceanogr 53:2350-2360

Boersma PD, Stokes DL, Strange IJ (2002) Applying ecology to conservation: tracking breeding penguins at New Island South Reserve, Falkland Islands. Aquat Conserv Mar Freshw Ecosyst 12:63-74

Bost CA, Cotté C, Bailleul F, Cherel Y, Charrassin JB, Guinet C, Ainley DG, Weimerskirch H (2009) The importance of oceanographic fronts to marine birds and mammals of the southern oceans. J Marine Syst 78:363-376

Cairns DK (1987) Seabirds as indicators of marine food supplies. Biol Oceanogr 5:261-271

Crawford RJM, Makhado AB, Upfold L, Dyer BM (2008) Mass on arrival of rockhopper penguins at Marion Island correlated with breeding success. Afr J Mar Sci 30:185-188

Crofts S, Stanworth A (2017) Falkland Islands seabird monitoring programme-annual report 2016/2017 (SMP24). Falklands Conservation, Stanley

Cunningham DM, Moors PJ (1994) The decline of Rockhopper Penguins Eudyptes chrysocome at Campbell Island, Southern Ocean and the influence of rising sea temperatures. EMU 94:27-36

Dehnhard N, Poisbleau M, Demongin L, Ludynia K, Lecoq M, Masello JF, Quillfeldt P (2013) Survival of Rockhopper penguins in times of global climate change. Aquat Conserv Mar Freshw Ecosyst 23:777-789

Dehnhard N, Eens M, Demongin L, Quillfeldt P, Poisbleau M (2015a) Individual consistency and phenotypic plasticity in rockhopper penguins: female but not male body mass links environmental conditions to reproductive investment. PLoS ONE 10:e0128776. https://doi.org/10.1371/journal.pone.0128776

Dehnhard N, Eens M, Demongin L, Quillfeldt P, Suri D, Poisbleau M (2015b) Limited individual phenotypic plasticity in the timing of and investment into egg laying in southern rockhopper penguins under climate change. Mar Ecol Prog Ser 524:269-281

Dehnhard N, Ludynia K, Masello JF, Voigt CC, McGill RAR, Quillfeldt $P$ (2016) Plasticity in foraging behaviour and diet buffers effects of inter-annual environmental differences on chick growth and survival in southern rockhopper penguins Eudyptes chrysocome chrysocome. Polar Biol 39:1627-1641

Emmerson L, Pike R, Southwell C (2011) Reproductive consequences of environment-driven variation in Adélie penguin breeding phenology. Mar Ecol Prog Ser 440:203-216

Forcada J, Trathan PN (2009) Penguin responses to climate change in the Southern Ocean. Glob Change Biol 15:1618-1630

Frederiksen M, Edwards M, Richardson AJ, Halliday HC, Wanless S (2006) From plankton to top predators: bottom-up control of a marine food web across four trophic levels. J Anim Ecol 75:1259-1268

Froget G, Butler PJ, Woakes AJ, Fahlman A, Kuntz G, Le Maho Y, Handrich Y (2004) Heart rate and energetics of free-ranging king penguins (Aptenodytes patagonicus). J Exp Biol 207:3917-3926

Garcia-Godos I, Goya E (2006) Diet of Peruvian Diving Petrels on La Vieja Island, central Peru, between 1997 and 2000, potential fishery interactions and conservation implications. Mar Ornithol 34:33-42

Green JA, Boyd IL, Woakes AJ, Warren NL, Butler PJ (2009) Evaluating the prudence of parents: daily energy expenditure throughout the annual cycle of a free-ranging bird, the macaroni penguin Eudyptes chrysolophus. J Avian Biol 40:529-538

Grémillet D, Boulinier T (2009) Spatial ecology and conservation of seabirds facing global climate change: a review. Mar Ecol Prog Ser 391:121-138 
Guinard E, Weimerskirch H, Jouventin P (1998) Population changes of the Northern Rockhopper Penguin on Amsterdam and Saint Paul Islands. Col Waterbirds 21:222-228

Hays GC, Richardson AJ, Robinson C (2005) Climate change and marine plankton. Trends Ecol Evol 20:337-344

Hilton GM, Thompson DR, Sagar PM, Cuthbert RJ, Cherel Y, Bury SJ (2006) A stable isotopic investigation into the causes of decline in a sub-Antarctic predator, the rockhopper penguin Eudyptes chrysocome. Glob Change Biol 12:611-625

Hull CL (1996) Morphometric indices for sexing adult Royal Eudyptes schlegeli and Rockhopper E. chrysocome penguins at Macquarie Island. Mar Ornithol 24:23-27

Hull CL, Hindell M, Le Mar K, Scofield P, Wilson J, Lea M-A (2004) The breeding biology and factors affecting reproductive success in rockhopper penguins Eudyptes chrysocome at Macquarie Island. Polar Biol 27:711-720

Lescroël A, Ballard G, Grémillet D, Authier M, Ainley DG (2014) Antarctic climate change: extreme events disrupt plastic phenotypic response in Adélie penguins. PLoS ONE 9:e85291. https ://doi.org/10.1371/journal.pone.0085291

Ludynia K, Dehnhard N, Poisbleau M, Demongin L, Masello JF, Quillfeldt P (2012) Evaluating the impact of handling and logger attachment on foraging parameters and physiology in southern rockhopper penguins. PLoS ONE 7:e50429. https:// doi.org/10.1371/journal.pone.0050429

Ludynia K, Dehnhard N, Poisbleau M, Demongin L, Masello JF, Voigt CC, Quillfeldt P (2013) Sexual segregation in rockhopper penguins during incubation. Anim Behav 85:255-267

Masello JF, Mundry R, Poisbleau M, Demongin L, Voigt CC, Wikelski M, Quillfeldt P (2010) Diving seabirds share foraging space and time within and among species. Ecosphere 1:1-28

Mattern T, Ellenberg U, Houston DM, Davis LS (2007) Consistent foraging routes and benthic foraging behaviour in yellow-eyed penguins. Mar Ecol Prog Ser 343:295-306

Morgenthaler A, Frere E, Raya Rey A, Torlaschi C, Cedrola P, Tiberi E, Lopez R, Mendieta E, Carranza ML, Acardi S, Collm N, Gandini P, Millones A (2018) Unusual number of Southern Rockhopper Penguins, Eudyptes chrysocome, molting and dying along the Southern Patagonian coast of Argentina: pre-molting dispersion event related to adverse oceanographic conditions? Polar Biol. https://doi.org/10.1007/s00300-018-2264-y

Morrison KW, Armstrong DP, Battley PF, Jamieson SE, Thompson DR (2017) Predation by New Zealand sea lions and Brown Skuas is causing the continued decline of an Eastern Rockhopper Penguin colony on Campbell Island. Polar Biol 40:735-751

Nakagawa S, Schielzeth H (2013) A general and simple method for obtaining R2 from generalized linear mixed-effects models. Methods Ecol Evol 4:113-142

Nakagawa S, Johnson PCD, Schielzeth H (2017) The coefficient of determination $\mathrm{R} 2$ and intra-class correlation coefficient from generalized linear mixed-effects models revisited and expanded. J R Soc Interface. https://doi.org/10.1098/rsif.2017.0213

Péron C, Weimerskirch H, Bost CA (2012) Projected poleward shift of king penguins' (Aptenodytes patagonicus) foraging range at the Crozet Islands, southern Indian Ocean. Proc. R. Soc. B 279:2515-2523

Pinheiro J, Bates D, DebRoy S, Sarkar D, R Core Team (2017) NLME: linear and nonlinear mixed effects models. $\mathrm{R}$ package version 3.1-131. https://CRAN.R-project.org/package=nlme

Poisbleau M, Demongin L, Strange IJ, Otley H, Quillfeldt P (2008) Aspects of the breeding biology of the southern rockhopper penguin Eudyptes c. chrysocome and new consideration on the intrinsic capacity of the A-egg. Polar Biol 31:925-932

Pütz K, Cherel Y (2005) The diving behaviour of brooding King Penguins (Aptenodytes patagonicus) from the Falkland Islands: variation in dive profiles and synchronous underwater swimming provide new insights into their foraging strategies. Mar Biol 147:281-290

Pütz K, Ingham RJ, Smith JG (2000) Satellite tracking of the winter migration of Magellanic Penguins Spheniscus magellanicus breeding in the Falkland Islands. Ibis 142:614-622

Pütz K, Ingham RJ, Smith JG, Croxall JP (2001) Population trends, breeding success and diet composition of gentoo Pygoscelis papua, magellanic Spheniscus magellanicus and rockhopper Eudyptes chrysocome penguins in the Falkland Islands. Polar Biol 24:793-807

Pütz K, Smith JG, Ingham RJ, Lüthi BH (2002) Winter dispersal of Rockhopper Penguins Eudyptes chrysocome from the Falkland Islands and its implications for conservation. Mar Ecol Prog Ser 240:273-284

Pütz K, Smith JG, Ingham RJ, Lüthi BH (2003) Satellite tracking of male Rockhopper Penguins Eudyptes chrysocome during the incubation period at the Falkland Islands. J Avian Biol 34:139-144

Pütz K, Raya Rey A, Schiavini A, Clausen AP, Lüthi BH (2006a) Winter migration of Rockhopper Penguins (Eudyptes c. chrysocome) breeding in the Southwest Atlantic: is utilisation of different foraging areas reflected in opposing population trends? Polar Biol 29:735-744

Pütz K, Raya Rey A, Huin N, Schiavini A, Pütz A, Lüthi BH (2006b) Diving characteristics of Southern Rockhopper Penguins (Eudyptes c. chrysocome) in the Southwest Atlantic. Mar Biol 149:125-137

Pütz K, Raya Rey A, Otley H (2013) Southern Rockhopper Penguin. In: García Borboroglu PG, Boersma PD (eds) Penguins-natural history and conservation. University of Washington Press, Seattle, pp 113-129

Pütz K, Trathan PN, Pedrana J, Collins MA, Poncet S, Lüthi BH (2014) Post-fledging dispersal of King Penguins (Aptenodytes patagonicus) from two breeding sites in the South Atlantic Ocean. PLoS ONE 9:e97164. https://doi.org/10.1371/journal.pone.0097164

Raya Rey A, Trathan P, Pütz K, Schiavini A (2007) Effect of oceanographic conditions on the winter movements of rockhopper penguins Eudyptes chrysocome chrysocome from Staten Island, Argentina. Mar Ecol Prog Ser 330:285-295

Raya Rey A, Rosciano N, Liljesthröm M, Saénz Samaniego R, Schiavini A (2014) Species-specific population trends detected for penguins, gulls and cormorants over 20 years in sub-Antarctic Fuegian Archipelago. Polar Biol 37:1343-1360

Richardson AJ, Schoeman DS (2004) Climate impact on plankton ecosystems in the Northeast Atlantic. Science 305:1609-1612

Ropert-Coudert Y, Knott N, Chiaradia A, Kato A (2007) How do different data logger sizes and attachment positions affect the diving behaviour of little penguins? Deep-Sea Res Pt II 54:415-423

Sabatini M, Martos P (2002) Mesozooplankton features in a frontal area off northern Patagonia (Argentina) during spring 1995 and 1998. Sci Mar 66:215-232

Sala JE, Pisoni JP, Quintana F (2017) Three-dimensional temperature fields of the North Patagonian Sea recorded by Magellanic penguins as biological sampling platforms. Estuar Coast Shelf Sci 189:203-215

Scheffer M, Carpenter SR (2003) Catastrophic regime shifts in ecosystems: linking theory to observation. Trends Ecol Evol 18:648-656

Sherley RB, Ludynia K, Dyer BM, Lamont T, Makhado AB, Roux JP, K1 Scales, Underhill LG, Votier SC (2017) Metapopulation tracking juvenile penguins reveals an ecosystem-wide ecological trap. Curr Biol 27:563-568

Smetacek V, Passow U (1990) Spring bloom initiation and Sverdrup's critical-depth model. Limnol Oceanogr 35:228-234

Stenseth NC, Mysterud A, Ottersen G, Hurrell JW, Chan KS, Lima M (2002) Ecological effects of climate fluctuations. Science 297:1292-1296 
Strange IJ (1982) Breeding ecology of the rockhopper penguin (Eudyptes crestatus) in the Falkland Islands. Gerfaut 72:137-188

Takahashi A, Dunn MJ, Trathan PN, Sato K, Naito Y, Croxall JP (2003) Foraging strategies of chinstrap penguins at Signy Island, Antarctica: importance of benthic feeding on Antarctic krill. Mar Ecol Prog Ser 250:279-289

Taylor SS, Leonard ML, Boness DJ, Majluf P (2001) Foraging trip duration increases for Humboldt Penguins tagged with recording devices. J Avian Biol 32:369-372

Thompson D, Sagar P (2002) Declining rockhopper penguin populations in New Zealand. Water Atmos 10:10-12

Thorne LH, Hazen EL, Bograd SJ, Foley DG, Conners MG, Kappes MA, Kim HM, Costa DP, Tremblay Y, Shaffer SA (2015) Foraging behaviour links climate variability and reproduction in North Pacific albatrosses. Mov Ecol 3:27. https://doi.org/10.1186/s4046 2-015-0050-9

Trathan PN, García-Borboroglu P, Boersma PD, Bost CA, Crawford RJM, Crossin GT, Cuthbert RJ, Dann P, Davis LS, de la Puente S, Ellenberg U, Lynch HJ, Mattern T, Pütz K, Seddon PJ, Trivelpiece W, Wienecke B (2014) Pollution, habitat loss, fishing and climate change as critical threats to penguins. Conserv Biol 29:31-41

Treasure AM, Roquet F, Ansorge IJ, Bester MN, Boehme L, Bornemann H, Charrassin JB, Chevallier D, Costa DP, Fedak MA, Guinet C, Hammill MO, Harcourt RG, Hindell MA, Kovacs KM, Lea MA, Lovell P, Lowther AD, Lydersen C, McIntyre T, McMahon CR, Muelbert MMC, Nicholls K, Picard B, Reverdin G, Trites AW, Williams GD, de Bruyn PJN (2017) Marine mammals exploring the oceans pole to pole: a review of the MEOP consortium. Oceanography 30:132-138

Tremblay Y, Cherel Y (2000) Benthic and pelagic dives: a new foraging behaviour in rockhopper penguins. Mar Ecol Prog Ser 204:257-267

Walther GR, Post E, Convey P, Menzel A, Parmesan C, Beebee TJC, Fromentin JM, Hoegh-Guldberg O, Bairlein F (2002) Ecological responses to recent climate change. Nature 416:389-395
Wcislo WT (1989) Behavioral environments and evolutionary change. Annu Rev Ecol Syst 20:137-169

Weimerskirch H (1995) Regulation of foraging trips and incubation routine in male and female wandering albatrosses. Oecologia 102:37-43

Williams TD (1995) The penguins. Oxford University Press, Oxford

Wilson RP (1995) Foraging ecology. In: Williams TD (ed) The penguins. Oxford University Press, Oxford, pp 81-106

Wilson RP, McMahon C (2006) Measuring devices on wild animals: what constitutes acceptable practice? Front Ecol Environ 4:147-154

Wilson RP, Pütz K, Bost CA, Culik BM, Bannasch R, Reins T, Adelung D (1993) Diel dive depth in penguins in relation to diel vertical migration of prey: whose dinner by candle light? Mar Ecol Prog Ser 94:101-104

Wilson RP, Pütz K, Peters G, Culik B, Scolaro JA, Charrassin JB, Ropert-Coudert Y (1997) Long-term attachment of transmitting and recording devices to penguins and other seabirds. Wildl Soc Bull 25:101-106

Wong BBM, Candolin U (2015) Behavioral responses to changing environments. Behav Ecol 26:665-673

Xavier JC, Trathan PN, Ceia FR, Tarling GA, Adlard S, Fox D, Edwards EW, Vieira RP, Medeiros R, De Broyer C, Cherel Y (2017) Sexual and individual foraging segregation in Gentoo penguins Pygoscelis papua from the Southern Ocean during an abnormal winter. PLoS ONE 12:e0174850. https://doi. org/10.1371/journal.pone.0174850

Ydenberg RC, Clark CW (1989) Aerobiosis and anaerobiosis during diving by western grebes: an optimal foraging approach. J Theor Biol 139:437-449 